\title{
Long-Legged Ants, Anoplolepis gracilipes (Hymenoptera: Formicidae), Have Invaded Tokelau, Changing Composition and Dynamics of Ant and Invertebrate Communities ${ }^{1}$
}

\author{
Pbilip 7. Lester ${ }^{2}$ and Alapati Tavite 3
}

\begin{abstract}
This report documents the ongoing invasion of the Tokelau atolls by the long-legged ant, Anoplolepis gracilipes (Jerdon). These ants were collected from two of the three Tokelau atolls. On the island of Fenua Fala of Fakaofo Atoll, long-legged ants appear to be a recent arrival and occur in only a small area around one of the two ports. Most of the inhabited islands of Vao and Motuhuga on Nukunonu Atoll have been invaded, in addition to several of the uninhabited, forested islands. Despite this ant having been previously recorded from at least one island of Fakaofo and Nukunonu, these appear to be new invasions. Densities of up to 3,603 $\mathrm{A}$. gracilipes per pitfall trap were caught per 24 hr. A significant reduction in ant species diversity was observed with increasing $A$. gracilipes densities. Densities of this ant were not uniformly high, perhaps due to variation in food availability. Prey such as crabs, ant colonies, and other insects were directly observed being attacked, and long-legged ants were observed to feed on honeydew produced by high densities of aphids, mealybugs, and scale insects on a variety of plants. Interspecific competition was investigated as an additional mechanism for the successful invasion. Long-legged ants found and removed bait faster than the dominant resident ant species, Paratrechina longicornis (Latreille), in forested areas of Nukunonu Island, though needing smaller numbers of recruits to achieve this result. This $A$. gracilipes invasion is of serious concern for the biodiversity of Tokelau and probably many of the other Pacific islands where these ants have invaded.
\end{abstract}

INVASIVE ANTS ARE thought to represent a major threat to biodiversity (Wetterer 1997, Christian 2001). However, not all ant species are invasive. Just six of the world's $\sim 9,000$ described ant species are commonly considered invasive, widespread, abundant, and damaging pests (Holway et al. 2002). One of these six invasive species is Anoplolepis gracilipes (Jerdon), the long-legged ant.

${ }^{1}$ Financial support was provided by Victoria University of Wellington and the Tokelau Department of Health. Manuscript accepted 23 June 2003.

2 School of Biological Sciences, Victoria University of Wellington, P.O. Box 600, Wellington, New Zealand (phone: +64-4-463-5096; fax: +64-4-463-5331; e-mail: phil.lester@vuw.ac.nz).

${ }^{3}$ Tokelau Department of Health, Main Office, $\mathrm{Nu}-$ kunonu, Tokelau.

Pacific Science (2004), vol. 58, no. 3:391-401

(C) 2004 by University of Hawai'i Press

All rights reserved
The origin of the long-legged ant is currently unknown, though it is thought likely to be either Asia (Wheeler 1910) or Africa (Wilson and Taylor 1967). As well as being abundant in those areas, it has invaded parts of Australia, the Caribbean, islands in the Indian Ocean, and the Pacific islands (Holway et al. 2002). The best-known invasions by A. gracilipes have occurred on the Seychelles (Haines et al. 1994), Christmas Island (Green et al. 1999), and Hawai'i (Fluker and Beardsley 1970). Those studies have shown that $A$. gracilipes has the potential to affect a wide variety of terrestrial flora and fauna. With an omnivorous diet, $A$. gracilipes is predaceous on both vertebrate and invertebrates species. It has been observed to attack and feed on other ants, other insects, spiders, crabs, and birds (Haines and Haines 1978, Gillespie and Reimer 1993, Feare 1999, Green et al. 1999). In addition, $A$. gracilipes can form mutualistic relationships with hemipteran insects result- 
ing in high densities of aphids, scale insects, or mealybugs sufficient to cause sooty mold on a variety of plant species (Rao et al. 1989). In areas where $A$. gracilipes has invaded, it may achieve extremely high densities of at least 10 million $\mathrm{ha}^{-1}$ (Haines and Haines 1978). The extreme abundance of these ants, combined with their omnivorous diet, has resulted in ecosystem change within some invaded areas. For example, in the absence of herbivorous crabs the forest on Christmas Island is becoming dense, while some tree species are dying off in areas as a result of extreme scale infestations (Green et al. 1999).

It is unknown why such high densities of these invasive ants occur, but the lack of coevolved natural enemies in novel habitat and reduced intraspecific aggression are likely mechanisms (Holway et al. 2002). It is often assumed that the high ant densities would enable these invaders to find and dominate any food sources more efficiently than resident species. Research on the invasive Argentine ant, Linepithema bumile (Mayr), has demonstrated that this species is superior at finding food (i.e., exploitative competition) (Holway 1999) and dominating food after its location (i.e., interference competition) (Human and Gordon 1996). A similarly strong exploitative and interference competitive ability has been observed for other common and successful invasive ants including Solenopis invicta (Buren) (Porter and Savignano 1990) and S. geminata (Fabricius) (Morrison 1999, 2000a). However, we do not know how the ability of $A$. gracilipes to find and utilize food relates to its ability to invade novel habitat.

The islands of Polynesia have been identified as a key area for poorly examined ant invasions (Wetterer 1997). Polynesia and Micronesia have been noted as a biodiversity hotspot containing $1.1 \%$ of known plant species and $0.8 \%$ of known vertebrates (Myers et al. 2000). Wilson and Taylor (1967) identified only 83 ant species in Polynesia. That species list includes several invaders known to be responsible for a substantial loss of biodiversity elsewhere, including $L$. bumile; the big-headed ant, Pbeidole megachephala (Fabricius); and the little fire ant, Wasmannia auropunctata (Roger). In addition, 14 archipelagoes were recorded as having $A$. gracilipes including islands from two atolls of Tokelau (Wilson and Taylor 1967, Hinckley 1969). Tokelau consists of three atolls, each containing a series of islands composing a total land area of about $12 \mathrm{~km}^{2}$, approximately 500 $\mathrm{km}$ north of Samoa. The most recent survey showed only 15 species of ants on these atolls (Hinckley 1969). However, residents have recently reported a problematic, new ant invasion.

Here, we examine the ongoing invasion of Tokelau by $A$. gracilipes. Specifically, each of the three atolls was examined for the presence of these ants. On one island of Nukunonu Atoll, where $A$. gracilipes has apparently recently invaded, we examined the invertebrate communities in invaded and as-yet-uninvaded areas. We also examined the relative ability of $A$. gracilipes to find and utilize food as a potential mechanism for understanding their invasion success.

\section{MATERIALS AND METHODS}

\section{Distribution of Long-legged Ants on Tokelau}

All three atolls of Tokelau were examined for the presence of $A$. gracilipes in November 2002. The primary mode of recent ant introduction to each atoll was almost certainly by boat because there is no airport on Tokelau. We searched for $A$. gracilipes ants in and around warehouses, urban areas, trees, and forested sections around ports where boats have unloaded. Searches consisted of a physical inspection and baiting with approximately $1 \mathrm{~cm}^{3}$ of canned tuna fish in oil. Baits were placed on the ground and examined over a 2-hr period between 0800 and 1800 hours. In places where $A$. gracilipes was established, its presence was generally obvious due to its distinctive large size, high densities, and frenzied and constant foraging behavior. Only in invasion fronts was $A$. gracilipes in lower densities and consequently somewhat less apparent. As a consequence of the conspicuous nature of these ants, local knowledge was also used to aid sampling around ports and in wider areas. Ants collected from all 
areas with the sampling methods described here were placed in $70 \%$ ethanol for identification under a binocular microscope at up to $100 \times$, using the keys of Wilson and Taylor (1967) and Bolton (1997).

\section{Density and Effects of A. gracilipes on Existing Ants and Other Artbropods}

The effects of $A$. gracilipes on existing arthropods were examined on Vao and Motuhunga Islands on Nukunonu Atoll. Those islands were selected because $A$. gracilipes had a wide distribution there, likely indicating that it had been present longer than on some of the other islands. Those islands have both forested and urban areas infested by $A$. gracilipes, as well as sections of forest as yet uninvaded. A bridge, which $A$. gracilipes was observed to traverse, connects these two islands.

Arthropods were sampled from three landuse types: forest with and without $A$. gracilipes and in the urban environment of Nukunonu village. Unfortunately no urban area was found that did not contain $A$. gracilipes. Three sampling sites were located within each of the three land-use types. Three to four pitfall traps were placed at each of the sites. Pitfall traps were separated by $10-20 \mathrm{~m}$ within a site, and each site was separated by at least $100 \mathrm{~m}$ from any other site. These traps were plastic drinking containers $90 \mathrm{~mm}$ high with a diameter of $70 \mathrm{~mm}$ at the top and $50 \mathrm{~mm}$ at the base. They were buried in the ground so that the lip was slightly below the substrate surface. Approximately $100 \mathrm{ml}$ of Gualt's solution was added to the cups. Gault's solution is an insect-killing agent and preservative, containing sodium chloride $(50 \mathrm{~g})$, chloral hydrate $(10 \mathrm{~g})$, and potassium nitrate $(10 \mathrm{~g})$ in 1,000 $\mathrm{ml}$ water (Walker and Crosby 1988). Traps were placed randomly without examination for ant nests. Initially we wanted to trap arthropods for $48 \mathrm{hr}$. However, where present large numbers of $A$. gracilipes were caught quickly, often filling a substantial portion of the container. Consequently all pitfall traps were removed after $24 \mathrm{hr}$. The entire contents of the pitfall traps were then washed into $70 \%$ ethanol for identification in the laboratory. Ants were identified to species as described earlier, but other arthropods were identified only to order.

The density of $A$. gracilipes was also examined in Apia, Samoa, using the same pitfall traps and design. Three sites in an urban area known to have an infestation of $A$. gracilipes were chosen, with three traps left at each site for $24 \mathrm{hr}$.

\section{Food Exploitation and Dominance Experiments}

The ability of $A$. gracilipes and other ants to find and utilize food was assessed using field observations of bait. Approximately 10 by 10 by $5 \mathrm{~mm}$ of tuna fish in oil was placed on the center of a card with a 70 by $70 \mathrm{~mm}$ grid drawn in pencil. The card edges were buried in the sandy substrate and left for $5 \mathrm{~min}$ before the addition of the bait. The time to bait discovery, and removal from the card, was measured. Discovery was defined as one ant touching the food, and removal as the entire bait being removed from the grid. In addition, the number of ants attending the tuna bait was estimated by photographing the grid at $1,2,4,8,15,30,60$, and 120 min after the bait was discovered by the ants. The placement of the bait traps was at the same sites using the same design as used for the pitfall traps: three to four baits were placed at each of the sites, separated by $10-20 \mathrm{~m}$; each site was separated by at least $100 \mathrm{~m}$ from any other site. Three replicates of this baiting experiment were undertaken at each of the three forested sites with and without longlegged ants. Some replicates were lost due to birds or lizards consuming the bait.

\section{Statistical Analysis}

Nested analysis of variance (ANOVA) was used to statistically analyze the effects of $A$. gracilipes on the abundance of insects, isopods, and crabs and to test for differences in the time taken for different ant species to find and remove the tuna baits. The nested feature was "site," because at least three replicate samples were taken at each of the three study sites in urban areas and areas of forest with or without $A$. gracilipes. Data were $\log$ transformed and examined for normality. Data used in 
the ANOVA were subsequently subjected to a power analysis, which explores the relationship between sample size and the probability of finding statistical significance (Systat 2002). Values of the power analysis ranged between 0 and 1 . A value of 0 indicates a $100 \%$ chance of committing a type II error (that the null hypothesis is false but not rejected), and a value of 1 indicates a $0 \%$ chance of committing this error. All power analyses were conducted at the significance level of 0.05 .

\section{RESULTS}

\section{Distribution of Long-legged Ants on Tokelau}

All three atolls of Tokelau were examined for $A$. gracilipes, which was found to have its widest distribution on Nukunonu Atoll. These ants covered nearly all of Nukunonu Island, with only a small area uninvaded around the hospital and in the center of the island. It seems likely that they are invading from around the port area of the village and from the northwestern area of the island, which contains a rubbish dump. Unfortunately one of the "forested sites with longlegged ants" chosen for pitfall trapping was later discovered to be placed near this invasion front in the center of the island. Observations by one of us (A.T.) since that time have shown an increase in $A$. gracilipes numbers at the site, and it has moved into previously uninvaded sites since these location data were collected (November and December 2002). In addition, on Nukunonu these ants were observed on the long island of Lalo, Hilakehe, and on Tokelau Island. On these three islands the entire ant distribution was not mapped.

Anoplolepis gracilipes appeared to have a limited distribution on Fakaofo Atoll. These ants were observed in only a few hectares around the port area of Fenua Fala Island. Within this area they were observed around the dock areas to the west of the island. No reports were obtained of $A$. gracilipes in the other islands within Fakaofo Atoll. On both Nukunonu and Fakaofo, A. gracilipes were observed to nest in coconut trees, under the ground substrate (generally consisting of broken coral or coarse sand, with some organic material), in urban structures, and in anthropogenic debris. Examined nests were polygyne, though the number of queens was not counted.

No evidence of $A$. gracilipes was observed on Atafu Atoll. A search was made expanding from the port area, but no $A$. gracilipes was observed. Local people indicated that they had not observed these ants on the atoll. Thus, there is no evidence that $A$. gracilipes ants have invaded Atafu.

\section{Density and Effects of A. gracilipes on Existing Ants and Other Organisms}

Where $A$. gracilipes populations had invaded, they often achieved very high densities. Pitfall traps placed in the field for only $24 \mathrm{hr}$ captured up to 3,603 of these ants. Such high densities were evident from the fact that tuna baits, lunch, or any field equipment placed on the ground were generally discovered by $A$. gracilipes within seconds. However, variation in the density of $A$. gracilipes was observed between sites (Figure 1). One of the causes for this variation was probably that one of the sites (F3, Figure 1) had been placed on an invasion front, as described earlier. Other sources of variation in the ant densities in the traps were most likely due to the location of randomly placed traps relative to the nearest ant nest.

Our sampling protocol allowed a sitespecific estimation of average ant species richness. Regression analysis demonstrated a significant linear relationship between $A$. gracilipes abundance and the number of other ant species observed at each site $(P=0.004$, Figure 1). The ant community observed in forested areas uninvaded by $A$. gracilipes was quite different from that in invaded areas. The most commonly encountered ant species in uninvaded areas was Tetramorium lanuginosum Mayr, followed by Paratrechina longicornis (Latreille) (Table 1). However, in invaded sites, $P$. longicornis was not observed in any of the pitfall traps and the percentage of sites where $T$. lanuginosum was observed was greatly reduced. Pheidole oceanica Mayr was another species apparently entirely absent 


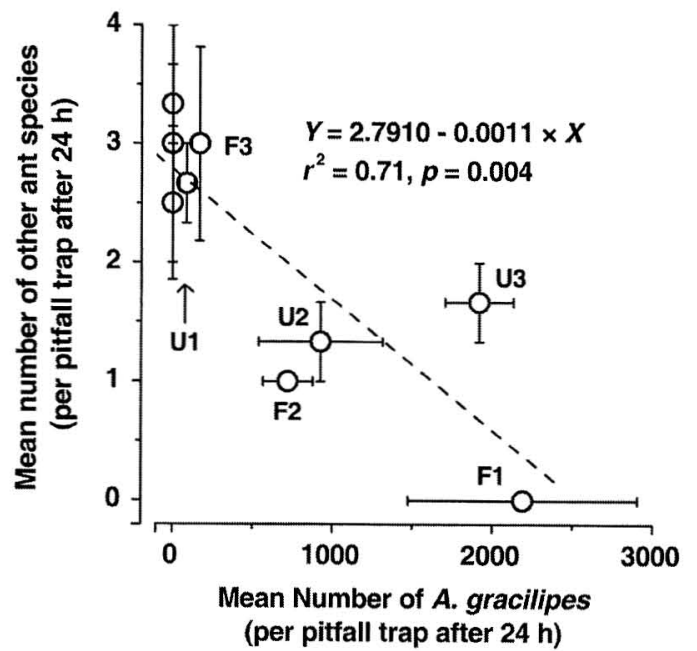

Figure 1. Relationship between mean number of $A$. gracilipes and mean number of other ant species, on a sitespecific basis. Each site contained three pitfall traps, operating for $24 \mathrm{hr}$. U1, U2, and U3 are the different sites in urban areas. $\mathrm{F} 1, \mathrm{~F} 2$, and $\mathrm{F} 3$ are forested sites with $A$. gracilipes. Forest sites without $A$. gracilipes are not differentiated. Error bars represent $1 \mathrm{SE}$. and apparently extirpated by $A$. gracilipes. Although not found in any of the pitfall traps, Camponotus chloroticus Emery was collected in coconut trees and on flowering Morinda citrifolia Linn. plants in areas uninvaded by $A$. gracilipes but not in invaded forest or urban sites. In urban sites species abundances were different than those in the forest. Tetramorium simillimum (Fr. Smith) was present at most of the urban sites, and Iridomyrmex anceps (Roger) was recorded for the first time from Tokelau.

Because it was possible to leave the pitfall traps in the ground for only $24 \mathrm{hr}$, this resulted in a limited number of other invertebrates being sampled in these containers. On average, only $\sim 2$ insects other than ants were observed in the forested sites, though more were observed in the urban sites (Figure 2). Commonly these insects were in the orders Diptera or Orthoptera. No significant differences were found in the number of insects caught between any of the different sites. Isopods were present in significantly higher densities in urban sites than in forest sites with no $A$. gracilipes. However, no sig-

TABLE 1

Mean Number of Ants Found in Each Pitfall Trap and Percentage of Traps in Which Each Species Was Observed

\begin{tabular}{|c|c|c|c|c|c|c|}
\hline \multirow[b]{2}{*}{ Ant Species } & \multicolumn{2}{|c|}{$\begin{array}{c}\text { Forest Sites without } \\
\text { A. gracilipes }\end{array}$} & \multicolumn{2}{|c|}{$\begin{array}{l}\text { Forest Sites with } \\
\text { A. gracilipes }\end{array}$} & \multicolumn{2}{|c|}{$\begin{array}{l}\text { Urban Sites with } \\
A . \text { gracilipes }\end{array}$} \\
\hline & $\begin{array}{l}\text { Mean No. } \\
\text { (SE) }\end{array}$ & $\begin{array}{l}\text { Sites } \\
(\%)\end{array}$ & $\begin{array}{l}\text { Mean No. } \\
\text { (SE) }\end{array}$ & $\begin{array}{l}\text { Sites } \\
(\%)\end{array}$ & $\begin{array}{l}\text { Mean No. } \\
\text { (SE) }\end{array}$ & $\begin{array}{l}\text { Sites } \\
(\%)\end{array}$ \\
\hline Anoplolepis gracilipes & - & - & $942(381)$ & 100 & $978(312)$ & 100 \\
\hline Tetramorium lanuginosum & $9.2(1.9)$ & 90 & $1.6(1.1)$ & 30 & $0.1(0.1)$ & 11 \\
\hline Paratrechina longicornis & $8.1(5.1)$ & 60 & - & - & $0.1(0.1)$ & 11 \\
\hline Pbeidole oceanica. & $2.7(1.6)$ & 30 & - & - & - & - \\
\hline Tetramorium simillimum & $2.1(2.1)$ & 10 & $0.1(0.1)$ & 10 & $37.7(16.7)$ & 78 \\
\hline Pheidole umbonata & $1.0(0.9)$ & 20 & $1.9(1.9)$ & 30 & $0.3(0.4)$ & 11 \\
\hline Paratrechina bourbonica & $0.7(0.5)$ & 20 & $0.3(0.2)$ & 20 & $0.1(0.1)$ & 11 \\
\hline Paratrechina vaga & $0.1(0.1)$ & 10 & $0.2(0.2)$ & 10 & $1.1(1.2)$ & 11 \\
\hline Rogeria stigmatica & $0.1(0.1)$ & 10 & - & - & - & - \\
\hline Monomorium floricola & - & - & - & - & $0.1(0.1)$ & 11 \\
\hline Iridomyrmex anceps & - & - & - & - & $0.3(0.3)$ & 22 \\
\hline Tapinoma melanocephalum & - & - & $0.1(0.1)$ & 10 & - & - \\
\hline Tetramorium bicarinatum & - & - & $3.5(2.0)$ & 40 & $0.2(0.2)$ & 22 \\
\hline
\end{tabular}

Note: Ant species arranged from most to least abundant in areas of forest uninvaded by $A$. gracilipes. Note that one of the forested sites with $A$. gracilipes was in an area later deemed to be an invasion front; this site contained a lower density of long-legged ants and a higher number of uther species. 


\section{(i) Total insect abundance}

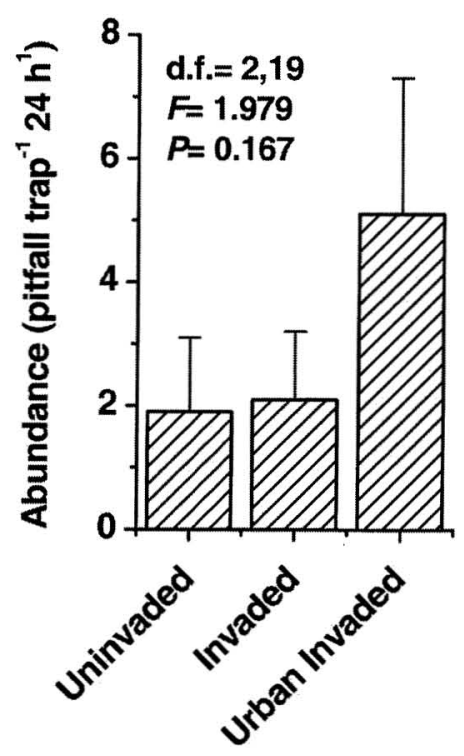

\section{(ii) Isopod} abundance

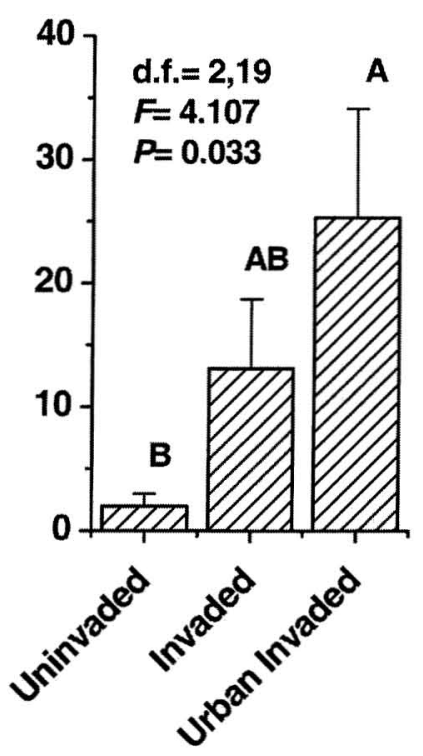

\section{(iii) Crab abundance}

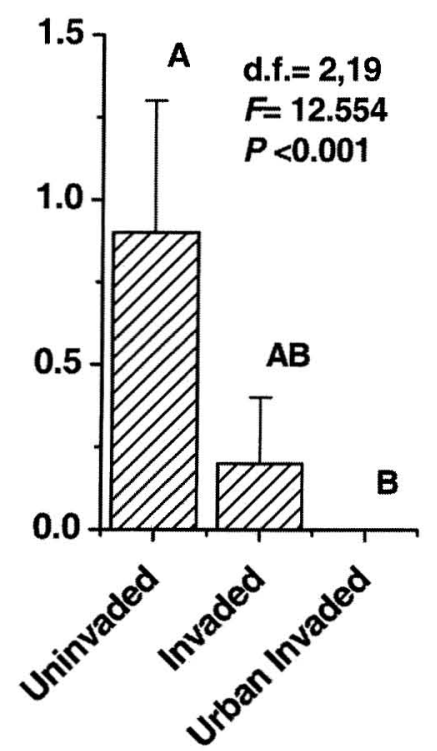

FIGURE 2. Abundance of insects, isopods, and crabs in forested areas with or without $A$. gracilipes and in the urban sites containing $A$. gracilipes, from pitfall traps operating for $24 \mathrm{hr}$. Error bars represent $1 \mathrm{SE}$.

nificant difference in isopod densities was observed in forested sites with or without $A$. gracilipes (Figure 2). In contrast to the isopods, the mean density of crabs (primarily hermit crabs) in invaded forest was approximately one-fourth of that observed in uninvaded forest, though they were entirely absent from the urban area (Figure 2). One crab was observed being attacked and killed by $A$. gracilipes at site $\mathrm{F} 3$. The statistical power analysis of the ANOVA examining crab abundance showed a $48.6 \%$ chance of committing a type II error, and the ANOVA for total insect and isopod densities showed a 49.6 and $6.8 \%$ chance, respectively. The number of samples estimated to be required to have an $80 \%$ chance of detecting a difference between all densities in the different areas was 20,16, and 6 for insects, crabs, and isopods, respectively.

At all sites where $A$. gracilipes was abundant, these ants had formed apparently mutualistic relationships with aphids, scale insects, or mealybugs. Dense scale infesta- tions were observed on banana, sufficiently high to cause the wilting of some banana palms. Similarly a wide variety of trees had dense infestations of mealybugs tended by A. gracilipes, and even small grasses had high aphid populations also tended by these ants.

In Apia, Samoa, three pitfall traps were placed at each of three sites for $24 \mathrm{hr}$ in urban areas infested by $A$. gracilipes, in a fashion similar to that of the Tokelau sampling. These Apia sites had a mean $A$. gracilipes density of $661 \pm 115$ SE (range 191-1,060, $n=8)$. For comparison, the mean density in urban areas of Tokelau was $997 \pm 293$ (range $57-2,040, n=9)$. These ant densities in urban sites of Apia and Nukunonu were not significantly different $(F=0.127 ; \mathrm{df}=1,15$; $P=0.726$ ).

\section{Food Exploitation and Dominance Experiments}

As described earlier, one of the forested sites had much lower densities of long-legged ants than the other two forested sites (site 
F3, Figure 1). This site appeared to be on the edge of an invasion front, evident from the food utilization experiments at this site. At all the other sites, the tuna bait was generally dominated by one species and utilized within $2 \mathrm{hr}$. At this site, however, A. gracilipes generally dominated the bait but $P$. longicornis, Paratrechina bourbonica (Forel), and Tetramorium bicarinatum (Nylander) also fed on the bait. Here, it appeared that $A$. gracilipes was unable to recruit large numbers of workers to dominate the bait. When a number of A. gracilipes did arrive on the grid, they spent much of their time attempting to fight off other ants from the bait rather than directly utilizing it. The baits were still present at the sites after at least $3 \mathrm{hr}$. Because this site was deemed to be on the invasion front, it was abandoned for the purpose of food utilization experiments. We wanted to focus instead on sites that appeared to have reached some equilibrium in ant abundance.

In forested areas of Nukunonu uninvaded by $A$. gracilipes, the crazy ant, Paratrechina longicornis, dominated the tuna bait in all replicates. Although other ants including $T$. bicarinatum and Pbeidole oceanica attempted to forage on the bait as well, these were attacked and chased away by $P$. longicornis. This species was nearly always the first to find the bait, taking an average of $141 \mathrm{sec}$ (range 45 to $442 \mathrm{sec}$ ) to discover the tuna bait in forested areas not inhabited by $A$. gracilipes. In invaded areas, $A$. gracilipes ants found the tuna bait after an average of $59 \mathrm{sec}$ (range 14 to 165 sec) (Figure 3). Due to the high amount of variation in these times, differences between species in food discovery were not significant $(F=2.509 ; \quad \mathrm{df}=1,11 ; P=0.141)$. A large proportion of the variation in bait discovery for both ant species is likely to be due to the random placement of sites, resulting in the baits being various distances from ant nests. The power analysis indicated that the high variation between samples resulted in a $73.1 \%$ chance of committing a type II error. To reduce this chance to $20 \%$, the analysis indicated that approximately 41 samples would need to be taken.

Where $A$. gracilipes had invaded successfully, it recruited to the baits faster but in fewer numbers than did $P$. longicornis. The average maximum number of $A$. gracilipes recruited was $43.2 \pm 7.3$ per bait, observed at the 15 -min interval. The maximum number of $P$. longicornis ants observed at the baits was $120.0 \pm 13.6$, at the 60 -min time interval (Figure 3). Despite recruiting fewer ants to the baits, long-legged ants utilized the bait faster than did $P$. longicornis. The bait was entirely removed from the grid after an average of $35.5 \mathrm{~min}$ (range 16 to $83 \mathrm{~min}$ ) by longlegged ants, approximately half the mean time of $P$. longicornis, which took $72 \mathrm{~min}$ (range 33 $\min$ to $139 \mathrm{~min}$ ) (Figure 3). Trails of $A$. gracilipes to and from the bait led toward different nests. It appeared that different nests of A. gracilipes were utilizing the bait and cooperating to defend it, without any sign of intraspecific aggression. Only after the tuna bait had been completely removed from the grid were other ant species such as T. bicarinatum able to forage on the grids where the bait had been placed, when only a small amount of oil was left on the grid paper. Individual ants of other species such as $T$. bicarinatum were periodically able to approach the bait, but were attacked by $A$. gracilipes or $P$. longicornis. Due to the high amount of variation in the samples, the nested ANOVA showed no significant differences between the times for each ant species to remove baits from the sites $(F=2.769 ; \quad \mathrm{df}=1,8 ; \quad P=0.133$ ) (Figure 3). The power analysis indicated that the high variation between samples resulted in a $63.3 \%$ chance of committing a type II error. To reduce this chance to $20 \%$, the analysis indicated that approximately 16 samples would need to be taken.

The tuna bait could be considered somewhat artificial because this fish is rarely observed lying on the forest floor. However, we observed $A$. gracilipes dominating other food sources in invaded areas. For example, the nectaries of Morinda citrifolia were entirely dominated by $A$. gracilipes in invaded areas. This ant was observed to feed on these nectaries during both day and night, with several ants occurring on most fruiting bodies. In contrast, however, $P$. longicornis was observed to share this resource with $C$. chloroticus and T. simillimum. 

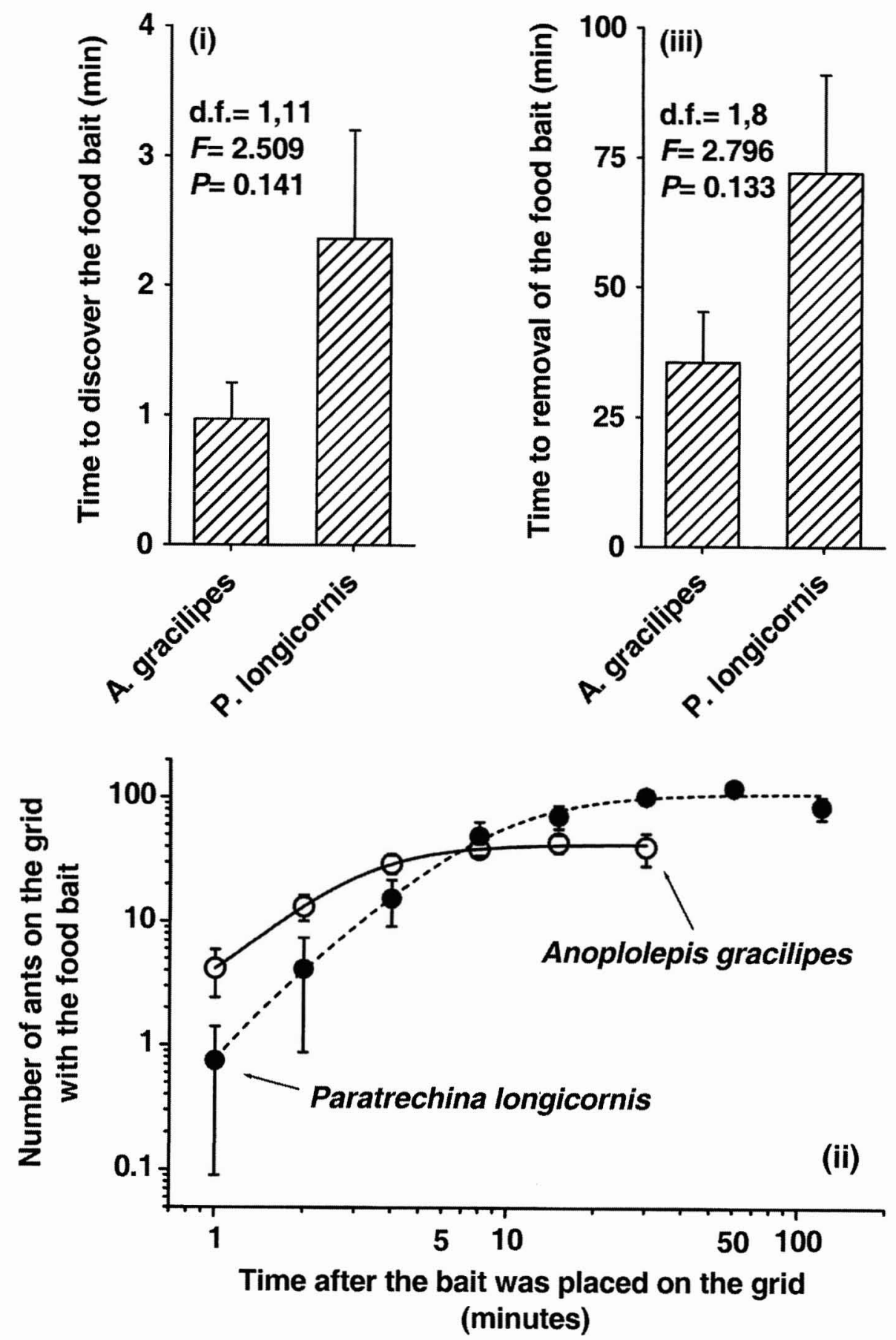

Figure 3. Differences in foraging behavior between $A$. gracilipes (in "invaded" sites) and the dominant existing ant Paratrechina longicornis (in "uninvaded" sites) on Nukunonu. $i$, Time until bait discovery after being placed on a paper grid. $i i$, Number of ants recruited to the baits, after discovery. The line of best fit is a sigmoidal curve. iii, Time until complete bait removal from the paper grids by each ant species. Error bars represent $1 \mathrm{SE}$. 


\section{DISCUSSION}

Anoplolepis gracilipes was observed at extremely high densities in some areas of Tokelau. Densities of up to 3,603 of these ants were caught in pitfall traps after only $24 \mathrm{hr}$. Similarly high densities of $A$. gracilipes have been observed elsewhere. Pitfall traps in the Seychelles caught a maximum of $\sim 80$ after $1 \mathrm{hr}$ (or $\sim 2,000$ per day) (Haines and Haines 1978). In comparison, the maximum total number of ants caught in any pitfall traps from noninvaded areas of Tokelau was 67.

These populations of $A$. gracilipes are likely to have arrived recently on the inhabited islands of both Nukunonu and Fakaofo, although they have been recorded on both atolls previously (Wilson and Taylor 1967, Hinckley 1969). We have two reasons for considered these to be new invasions on these particular islands within the atolls. First, only recently have people noticed their presence in urban environments and the invasion fronts were observed to be still spreading on the islands. Inhabitants of Fakaofo Atoll have been burning trees with high infestations of $A$. gracilipes on Fenua Fala Island in an attempt to slow its invasion rate. Second, there are areas on islands of both infested atolls that are currently free of $A$. gracilipes, though since this work was undertaken we have observed these ants move farther into these uninfested zones. These apparently new $A$. gracilipes infestations likely came from Samoa because large infestations of this ant were observed in produce stored in the warehouse for transport on the boat to Tokelau. This boat is certainly a carrier of ants to the island because while traveling on the boat for this study one of us (P.J.L) recorded the presence of the species Monomorium minutum Mayr, $P$. vaga, and $T$. bicarinatum in just four small potted plants being moved to Nukunonu during November 2002. It is also possible that these new $A$. gracilipes invasions stem from other islands within the atolls or that the increase in their abundance and distribution is being facilitated by the invasion of a mutualistic species such as a hemipteran insect.

The mechanism whereby invasive ants can become so abundant remains unknown.
Three factors are thought to contribute to their high abundance: a lack of coevolved natural enemies, unicolonality leading to reduced interspecific competition in invaded habitat, and efficient utilization of resources (Holway et al. 2002). It seems unlikely that coevolved natural enemies would have arrived in Tokelau with $A$. gracilipes. Unicolonality has been observed for $A$. gracilipes on Christmas Island (Green et al. 1999). Little intraspecific competition appeared to be occurring with $A$. gracilipes in Tokelau because ants apparently from different nests were observed to cooperate in feeding on baits. Resources such as homopteran insects appeared to be dominated by $A$. gracilipes on Tokelau. The dominant ant in uninvaded areas, $P$. longicornis, was observed to share resources such as extrafloral nectaries with other ant species. Observations of the tuna baits indicated that $A$. gracilipes was able to utilize the same amount of food much faster and in lower numbers than did $P$. longicornis. This result may be somewhat expected because $A$. gracilipes is approximately 1.6 times as large as $P$. longicornis. It thus seems likely that all three mechanisms for achieving high ant numbers have contributed to the abundance of $A$. gracilipes in Tokelau.

Densities of $A$. gracilipes were not uniformly high throughout the study sites. Part of this variation was due to one of the study sites being unknowingly placed on an invasion boundary. However, the density of these ants was variable even at some sites well inside the boundary. Greenslade (1971) also observed variation in the abundance of this ant and attributed it to spatial variation in potential nest sites or food availability. A similar situation appears to have developed on Christmas Island: extremely high abundances develop only where the invasive lac scale $T a$ chardina aurantiaca (Cockerell) occurs in high abundance (Green et al. 1999). On Tokelau, $A$. gracilipes was observed feeding on a range of scale insects, mealybugs, and aphids. Variation in the distribution of host plants for these homopterans, in addition to variation of the utilization of these plants, may thus be the cause for the spatial variation in $A$. gracilipes densities. Nesting sites appeared less limiting. 
The soil of Tokelau is not well developed (Hinckley 1969), and A. gracilipes appeared to have little trouble nesting in this substrate and around roots of trees or in coconut palms.

Where high densities of $A$. gracilipes did occur, they were correlated with a significantly reduced occurrence of other ant species and the apparently complete extirpation of others. Elsewhere, $A$. gracilipes has been observed to extirpate other ant species, by either competition or direct predation (Phillips 1956, Greenslade 1971, Soans and Soans 1971, Rao et al. 1989). Laboratory studies have indicated that $A$. gracilipes needs ratios greater than $5: 1$ to be successful in attacking species such as Camponotus maculatus Forel (Haines and Haines 1978). It seems likely that the ant species suffering the most are those with an ecological niche similar to that of $A$. gracilipes, although at the highest $A$. gracilipes density no other ant species were observed. Because no study was undertaken before invasion, we cannot be entirely sure of the community composition at this site before $A$. gracilipes invasion. However, it seems likely that some of the other ant species would have existed at these sites before invasion.

Other organisms also appeared to be influenced by the invasion of these ants. Observations indicated that crab populations were reduced, but not significantly so, in forested areas invaded by $A$. gracilipes. Crab densities can be reduced as a result of direct predation (Green et al. 1999), although there is some evidence that competition between crabs and ants for food can also occur (Morrison 2002b). Elsewhere, isopod populations have been observed to increase as a result of the presence of $A$. gracilipes (Haines and Haines 1978, Rao et al. 1989). Total insect abundance was not significantly different between sites, although there were very few insects other than ants found in the pitfall traps after only $24 \mathrm{hr}$. Elsewhere invasions of $A$. gracilipes have been associated with reduced densities of spiders and insects (Rao et al. 1989, Gillespie and Reimer 1993), to the point where these ants have been utilized for biological control programs (Baker 1976). In our Tokelau study, the lack of significant effects for some of the groups could have been due to the small number of samples taken, but also as a result of the variation in $A$. gracilipes densities as described earlier. The power analyses indicated that up to 41 samples would be needed in some of the experimental treatments to have an $80 \%$ probability of detecting a difference between population means. This high number of samples reflects the high spatial variation in densities of $A$. gracilipes in Tokelau. The exact mechanisms for such spatial variation in ant densities remains to be determined.

Invasions of $A$. gracilipes have been known to change communities drastically (Green et al. 1999). Although we observed variation in densities and effects of this ant on Tokelau, such invasions into this and other Pacific islands are of major concern for the flora and fauna. The last review of the ants on Nukunonu Atoll showed only seven ant species (Hinckley 1969). In this small study we have identified six new ant species on this atoll, including species such as Iridomyrmex anceps and $P$. longicornis. Movement of people and goods around the Pacific is enhancing ant movement, as we found for Monomorium minutum while traveling on the boat from Samoa to Tokelau. The Pacific is an area of high endemic biodiversity (Myers et al. 2000) that is proving highly susceptible to ant invasions.

\section{ACKNOWLEDGMENTS}

We thank Peter Adams, Kele Kelekolio for guidance on Fakaofo Atoll, and the people and Council of Elders of Tokelau for their assistance with this project. We thank Jo Love for technical assistance; John Brightwell; Catherine Duthie; Stephen Hartley, who reviewed a draft of the manuscript; and John Haywood for statistical advice.

\section{Literature Cited}

Baker, G. L. 1976. The seasonal life cycle of Anoplolepis longipes (Jerdon) (Hymenoptera: Formicidae) in a cacao plantation and under a brushed rain forest in the northern district of Papua New Guinea. Insect Soc. 23:253-262.

Bolton, B. 1997. Identification guide to the 
ant genera of the world. Harvard University Press, Cambridge, Massachusetts.

Christian, C. E. 2001. Consequences of a biological invasion reveal the importance of mutualism for plant communities. Nature (Lond.) 413:635-639.

Feare, C. 1999. Ants take over from rats on Bird Island, Seychelles. Bird Conserv. Int. 9:95-96.

Fluker, S. S., and J. W. Beardsley. 1970. Sympatric associations of three ants: Iridomyrmex bumilis, Pheidole megachephala, and Anoplolepis longipes in Hawaii. Ann. Entomol. Soc. Am. 63:1290-1296.

Gillespie, R. G., and N. Reimer. 1993. The effect of alien predatory ants (Hymenoptera: Formicidae) on Hawaiian endemic spiders (Araneae: Tetragnathidae). Pac. Sci. 47:21-33.

Green, P. T., D. J. O'Dowd, and P. S. Lake. 1999. Alien ant invasion and ecosystem collapse on Christmas Island, Indian Ocean. Aliens 9:2-4.

Greenslade, P. J. M. 1971. Interspecific competition and frequency changes among ants in a Solomon Islands coconut plantation. J. Appl. Ecol. 8:322-349.

Haines, I. H., and J. B. Haines. 1978. Pest status of the crazy ant, Anoplolepis longipes (Jerdon) (Hymenoptera: Formicidae), in the Seychelles. Bull. Entomol. Res. 68: 627-638.

Haines, I. H., J. B. Haines, and J. M. Cherrett. 1994. The impact and control of the crazy ant, Anoplolepis longipes (Jerd.), in the Seychelles. Pages 207-218 in D. F. Williams, ed. Exotic ants: Biology, impact, and control of introduced species. Westview Press, Boulder, Colorado.

Hinckley, A. D. 1969. Ecology of terrestrial arthropods in the Tokelau Atolls. Atoll Res. Bull. 124:1-18.

Holway, D. A. 1999. Competitive mechanisms underlying the displacement of native ants by the invasive Argentine ant. Ecology 80:238-251.

Holway, D. A., L. Lach, A. V. Suarez, N. D. Tsutsui, and T. J. Case. 2002. The causes and consequences of ant invasions. Annu. Rev. Ecol. Syst. 33:181-233.

Human, K. G., and D. M. Gordon. 1996. Exploitation and interference competition between the invasive Argentine ant, Linepithema bumile, and native ant species. Oecologia (Berl.) 105:405-412.

Morrison, L. W. 1999. Indirect effects of phorid fly parasitoids on the mechanisms of interspecific competition among ants. Oecologia (Berl.) 121:113-122.

2000a. Mechanisms of interspecific competition among an invasive and two native fire ants. Oikos 90:238-252.

- 2002b. Interspecific competition and coexistence between ants and land hermit crabs on small Bahamian islands. Acta Oecol. 23:223-229.

Myers, N., R. A. Mittermeier, C. G. Mittermeier, G. A. B. da Fonseca, and J. Kent. 2000. Biodiversity hotspots for conservation priorities. Nature (Lond.) 403:853858.

Phillips, J. S. 1956. Immature nut fall of coconuts in the British Solomon Islands protectorate. Bull. Entomol. Res. 47:575595.

Porter, S. D., and D. A. Savignano. 1990. Invasion of polygne fire ants decimates native ants and disrupts arthropod community. Ecology 71:2095-2106.

Rao, N. S., G. K. Veeresh, and C. A. Viraktamath. 1989. Association of crazy ant, Anoplolepis longipes (Jordon), with different flora and fauna. Indian J. Ecol. 16:205208.

Soans, A. B., and J. S. Soans. 1971. A case of intergeneric competition and replacement in the ants Oecopbylla smaragdina Fabricius and Anoplolepis longipes Jerdon (Hymenoptera: Formicidae). J. Bombay Nat. Hist. Soc. 68:289-290.

Systat. 2002. Systat 10.2. Systat Software Inc., Richmond, California.

Walker, A. K., and T. K. Crosby. 1988. The preparation and curation of insects. DSIR Information Series 163. Entomology Division, DSIR, Auckland, New Zealand.

Wetterer, J. K. 1997. Alien ants of the Pacific islands. Aliens 6:3-4.

Wheeler, W. M. 1910. Ants: Their structure, development and behaviour. Columbia University Press, New York.

Wilson, E. O., and R. W. Taylor. 1967. The ants of Polynesia (Hymenoptera: Formicidae). Pac. Insects Monogr. 14:1-109. 